ORNLTM-13126

OAK RIDGE

UEC 281005

OSTI

NATIONAL

LABORATORY

MARTIN MARHETTA

Design Plan for Development of the Worldwide Port System (WPS)

Regional Integrated Cargo Database (ICDB)
L. F. Truett
J. P. Rollow
P. C. Shipe
E. Z. Faby
J. Fluker
J. W. Grubb
R. A. Ferguson

MANAGED BY

MARTIN MARIETTA ENERGY SYSTEMS, INC.

FOR THE UNITED STATES

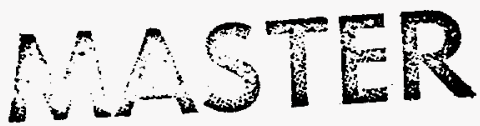

DEPARTMENT OF ENERGY 
This report has ben reproduced directly from the best available copy.

Available to DOE and DOE contractors from the Office of Scientific and Technical Information, P.O. Box 62, Oak Ridge, TN 37831 ; prices available from (615) 576-8401, FTS 626-8401.

Available to the public from the National Technical Information Service, U.S. Department of Commerce, 5285 Port Royal Rd., Springfield, VA 22161.

This report was prepared as an account of work sponsored by an agency of the United States Government. Neither the United States Government nor any agency thereot, nor any of their employees, makes any warranty, express or implied, or assumes any legal liability or responsibility for the accuracy, com pleteness, or usefulness of any information, apparatus, product, or process disclosed. or represents that its use would not iniringe privately owned rights. Reference herein to any specific commercial product, process, or service by trade name, trademark, manufacturer, or otherwise, does not necessarily constitute or imply its endorsement, recommendation, or favoring by the United States Government or any agency thereof. The views and opinions of authors expressed herein do not necessarily state or rellect those of the United States Government or any agency thereot. 


\section{DISCLAMMER}

Portions of this document may be illegible in electronic image products. Images are produced from the best available original document. 
Energy Division

\title{
DESIGN PLAN FOR DEVELOPMENT OF THE WORLDWIDE PORT SYSTEM (WPS) REGIONAL INTEGRATED CARGO DATABASE (ICDB)
}

\author{
L. F. Truett J. P. Rollow P. C. Shipe \\ Oak Ridge National Laboratory \\ E. Z. Faby J. Fluker J. W. Grubb \\ University of Tennessee, Knoxville \\ R. A. Ferguson \\ SAIC, Oak Ridge, Tennessee
}

November 1995

Prepared for the

Product Management Office

Office of the Deputy Chief of Staff for Information Management

MILITARY TRAFFIC MANAGEMENT COMMAND

Falls Church, Virginia 22041-5050

under

Interagency Agreement DOE No. 1405-1351-A1

Prepared by the

OAK RIDGE NATIONAL LABORATORY

Oak Ridge, Tennessee 37831

managed by

LOCKHEED MARTIN ENERGY SYSTEMS, INC.

for the

U.S. DEPARTMENT OF ENERGY

under contract DE-AC05-84OR21400 


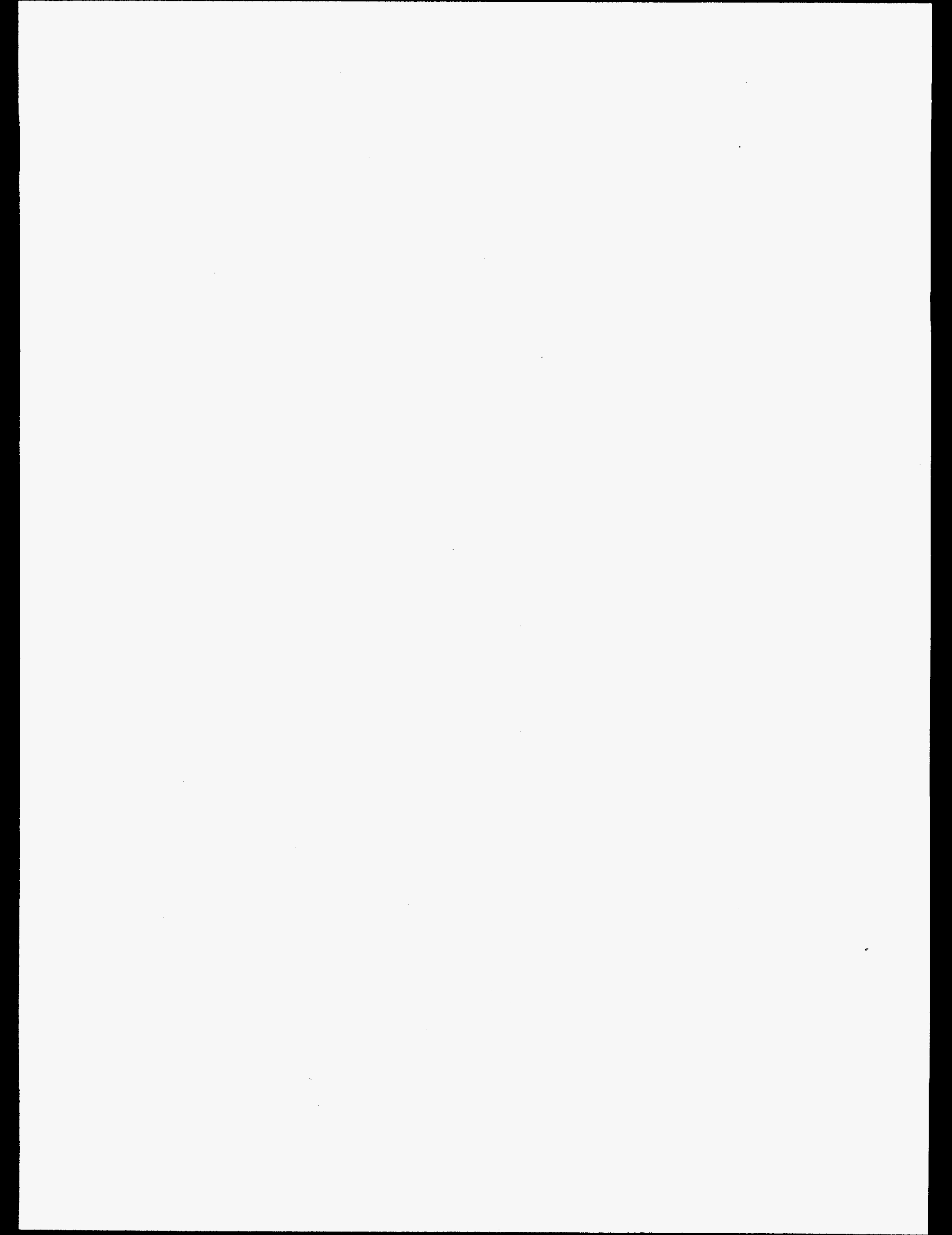




\section{CONTENTS}

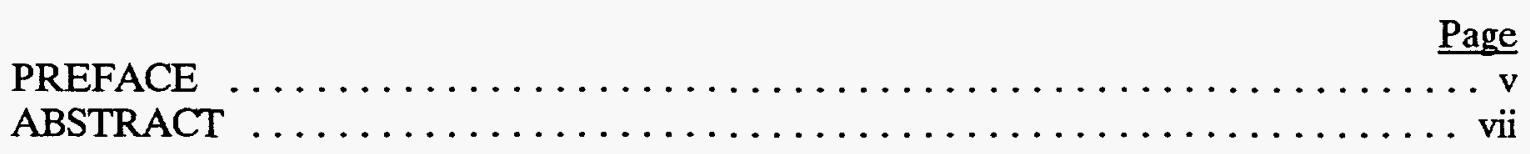

1. INTRODUCTION $\ldots \ldots \ldots \ldots \ldots \ldots \ldots \ldots \ldots \ldots \ldots \ldots \ldots \ldots \ldots \ldots \ldots$

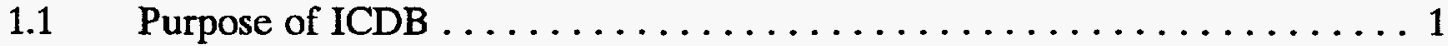

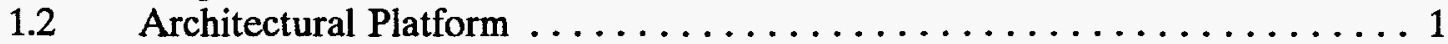

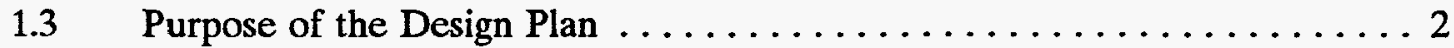

1.4 Basic Strategy for ICDB Design and Development .............. 2

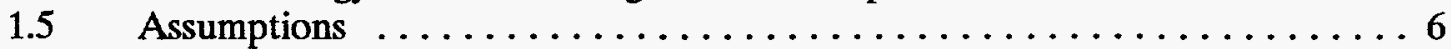

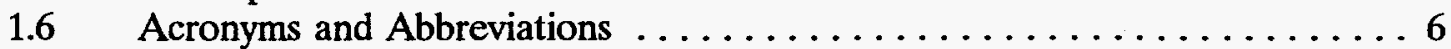

$1.7 \quad$ References $\ldots \ldots \ldots \ldots \ldots \ldots \ldots \ldots \ldots \ldots \ldots \ldots \ldots \ldots$

2. DEVELOPMENT STRATEGY: FUNCTIONAL REQUIREMENTS $\ldots \ldots \ldots 9$

$2.1 \quad$ ATCMD Processing . . . . . . . . . . . . . . . . . . 9

2.1.1 Design and development tasks $\ldots \ldots \ldots \ldots \ldots \ldots \ldots \ldots \ldots \ldots$

2.1 .2 Responsibilities . . . . . . . . . . . . . . . 12

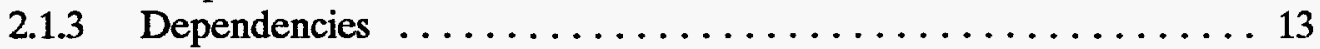

2.1.4 Development Schedule ..................... 13

2.2 Import Manifest Decomposition and Distribution . . . . . . . . . . 14

2.2.1 Design and development tasks . . . . . . . . . . . . . 14

2.2 .2 Responsibilities . . . . . . . . . . . . . . . . 16

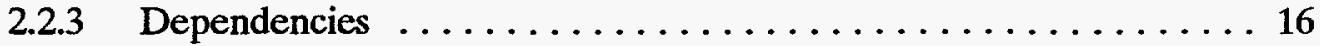

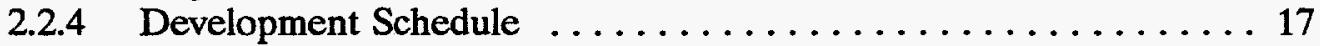

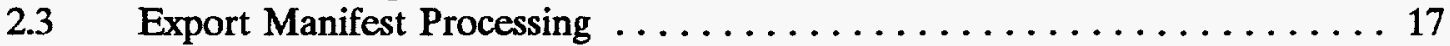

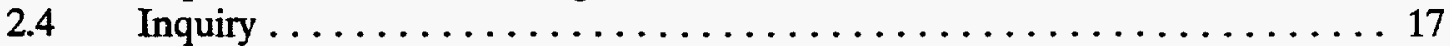

2.4.1 Design and development tasks .................. 19

2.4 .2 Responsibilities ........................... 20

2.4 .3 Dependencies ........................ 20

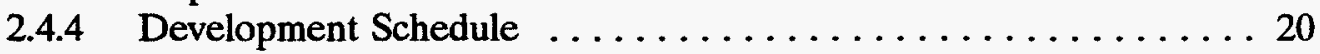

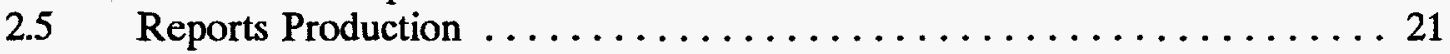

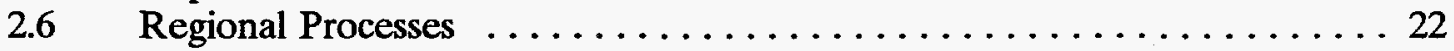

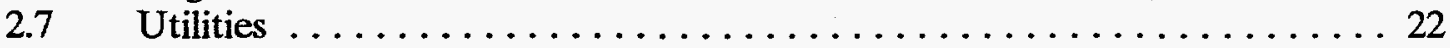

3. DEVELOPMENT STRATEGY: SYSTEM REQUIREMENTS $\ldots \ldots \ldots \ldots \ldots 23$

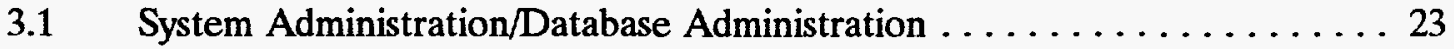

3.1.1 Design and development tasks .................. 25

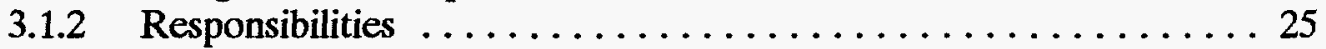

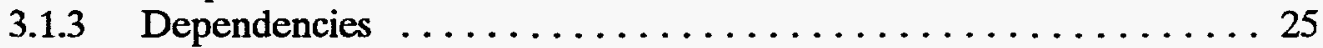

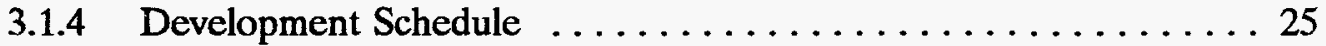

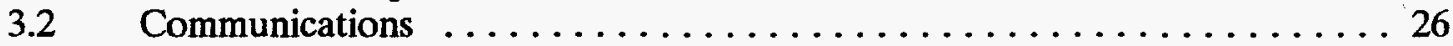

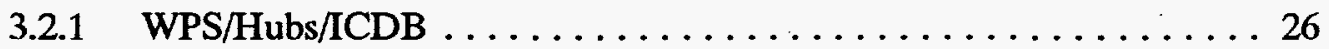

3.2.1.1 Design and development tasks . . . . . . . . . . 27

3.2.1.2 Responsibilities ........................ 29

3.2.1.3 Dependencies ................... 29 


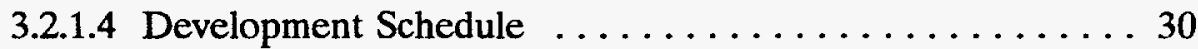

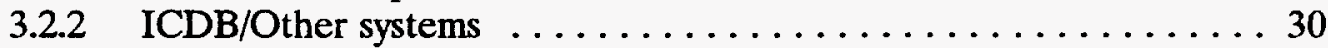

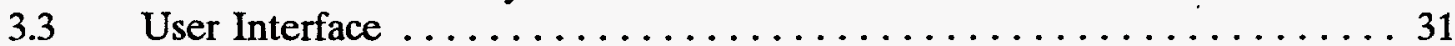

3.3.1 Design and development tasks $\ldots \ldots \ldots \ldots \ldots \ldots \ldots \ldots \ldots \ldots \ldots$

3.3.2 Responsibilities ........................ 31

3.3.3 Dependencies ....................... 32

3.3.4 Development Schedule ................... 32

Appendix A ICDB TESTING SCHEDULE $\ldots \ldots \ldots \ldots \ldots \ldots \ldots \ldots \ldots \ldots$

\section{LIST OF FIGURES}

Figure $\underline{\text { Page }}$

1.1 Location of database tables and processing modules, IOC processes . . . . 4

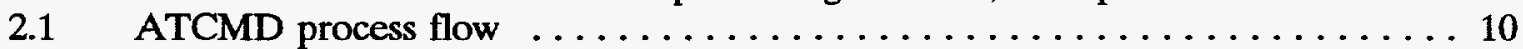

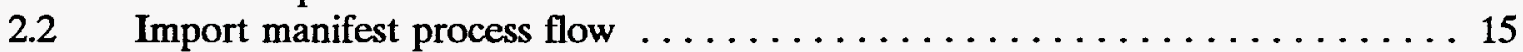

\section{LIST OF TABLES}

Table

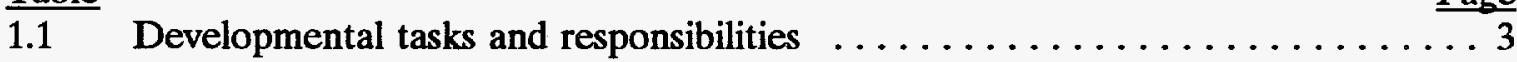

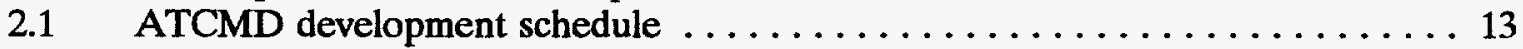

2.2 Import manifest processing development schedule $\ldots \ldots \ldots \ldots \ldots \ldots \ldots \ldots$

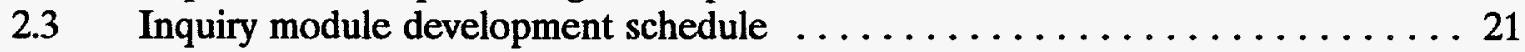

3.1 System and database administration modules $\ldots \ldots \ldots \ldots \ldots \ldots \ldots \ldots \ldots$

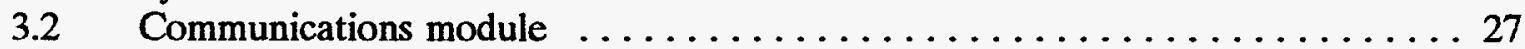

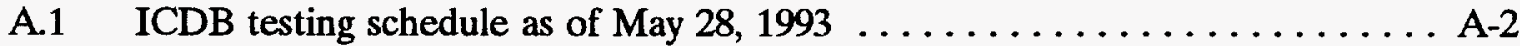

A.2 Formal testing schedule of the WPS Regional ICDB $\ldots \ldots \ldots \ldots \ldots \ldots$ A-3 


\section{PREFACE}

The Design Plan was completed in May 1993 and was used during development of the Worldwide Port System (WPS) Regional Integrated Cargo Database (ICDB). This version, which is a revision of the original Design Plan, incorporates changes in responsibilities which occurred during development. The original (planned) schedules remain in each subsection with their original time frames, and an updated actual time frame for final testing is also provided in Appendix A.

Contributions of personnel from Military Traffic Management Command (MTMC) Eastern Area (led Mike Sturm) in Bayonne, New Jersey, and MTMC Product Management Office (primarily Lisa Seery and Jack Hetman) in Falls Church, Virginia, to the original text of this document are acknowledged. 


\begin{abstract}
The Worldwide Port System (WPS) Regional Integrated Cargo Database (ICDB) is a major military computer system that provides visibility over international cargo. Development started in early 1993 and implementation began on the West Coast in August of 1995.

The Design Plan coordinated developmental efforts for the ICDB and its related processes. A Design Plan was especially important because the ICDB was developed at multiple sites by Oak Ridge National Laboratory and Military Traffic Management Command personnel. A Design Plan was essential to ensure that a consistent design was maintained throughout all modules, that functional and technical requirements were accomplished, that all components and processes worked together successfully, and that the development schedule was met. This plan described ICDB modules and tasks within each module. It documented responsibilities and dependencies by module and presented a schedule for development, testing, and integration.
\end{abstract}




\section{INTRODUCTION}

\subsection{PURPOSE OF ICDB}

The Worldwide Port System (WPS) Regional Integrated Cargo Database (ICDB) was designed and developed by the Military Traffic Management Command (MTMC) and personnel from Oak Ridge National Laboratory (ORNL). ICDB provides data integration and worldwide tracking of cargo that passes through common-user ocean cargo ports. ICDB is a data repository for the WPS terminal-level system, is a primary source for queries and cargo traffic reports, receives data from and provides data to other MTMC and non-MTMC systems, provides capabilities for processing Advance Transportation Command and Movement Documents (ATCMDs), distributes manifests, and provides regional managers with capabilities for managing cargo and monitoring cargo information. ICDB provides an integrated database for efficient and reliable data management, data manipulation, and data distribution.

\subsection{ARCHITECTURAL PLATFORM}

ICDB conforms to the requirements of Autostrad-2000 (A-2000), which implies an open systems design. Unix is the operating system, and Oracle7 is the relational database management system (RDBMS). Various Oracle tools were used for development, including the Oracle Computer Aided Software Engineering (CASE) tool, Oracle SQL*Forms, Oracle SQL*Menu, Oracle Reportwriter, Oracle PL*SQL, and Oracle SQL*Net. Other Oracle products (e.g., Oracle Browser) or additional third-party-vendor tools (e.g., graphical user interfaces) may also be used in the future; however, they were not used during development of initial operating capability (IOC). Third-generation (3GL) procedural code, when required, was Ada. A third-party vendor product, Intelligent Query $(\mathrm{IQ})^{1}$ was used to provide ad hoc query capability.

${ }^{1} \mathrm{IQ}$ is a product of Programmed Intelligence Corporation, Norcross, Georgia. 
The basic ICDB architectural design is a single worldwide central database server and multiple regional processing hubs. The primary source of data to ICDB is from the WPS terminal-level system, located at the ports.

\subsection{PURPOSE OF THE DESIGN PLAN}

This project was directed by the MTMC Office of the Deputy Chief of Staff for Information Management ICDB Product Management Office (PMO). Technical design and development activities were being cooperatively developed by staff at MTMC Information Management - Eastern Area (IME) and ORNL. MTMC personnel involved in the development of WPS provided functional and technical assistance and were closely involved during final development, integration, and testing.

Because ICDB was developed at multiple sites, this Design Plan was written to coordinate the development activities. Various documents exist which describe the functional requirements, architectural platform, and database specification of ICDB and/or WPS; these are referenced in Section 1.7. In addition, a Standards and Conventions report describes ICDB screen appearance, programming conventions, and other design guidelines (Section 1.7). The information contained in other documents is not repeated in this report except when necessary to describe a design process.

\subsection{BASIC STRATEGY FOR ICDB DESIGN AND DEVELOPMENT}

As noted in Section 1.3, ORNL and IME were assigned development tasks by the PMO. Specific tasks and responsibilities for development of each functional and system-level process are described in more detail in Sections 2 and 3, respectively. Table 1.1 presents these tasks and responsibilities in broad categories. 
Table 1.1. Developmental tasks and responsibilities.

\begin{tabular}{||l|l||}
\hline \multicolumn{1}{|c|}{ Process } & \multicolumn{1}{c|}{ Responsibility } \\
\hline ATCMD processing & IME \\
\hline Import manifest decomposition and distribution & IME \\
\hline Export manifest processing & IME (originally); WPS \\
\hline Queries & ORNL \\
\hline Regional processes & ORNL and IME \\
\hline Reports production & ORNL and IME \\
\hline System, data, and database administration processes & ORNL \\
\hline Communications and data exchanges & ORNL \\
\hline User interface & ORNL \\
\hline
\end{tabular}

The development strategy described in this report was based on the design presented in the ICDB Architectural Analysis (i.e., a central database server and regional processing hubs). Figure 1.1 shows the processes located at the hubs and at the central database. Communications between WPS sites and hubs and between hubs and the central ICDB was via Oracle's SQL*Net for most processes. It should be noted that Figure 1.1 represents IOC for the Continental United States (CONUS) only. 


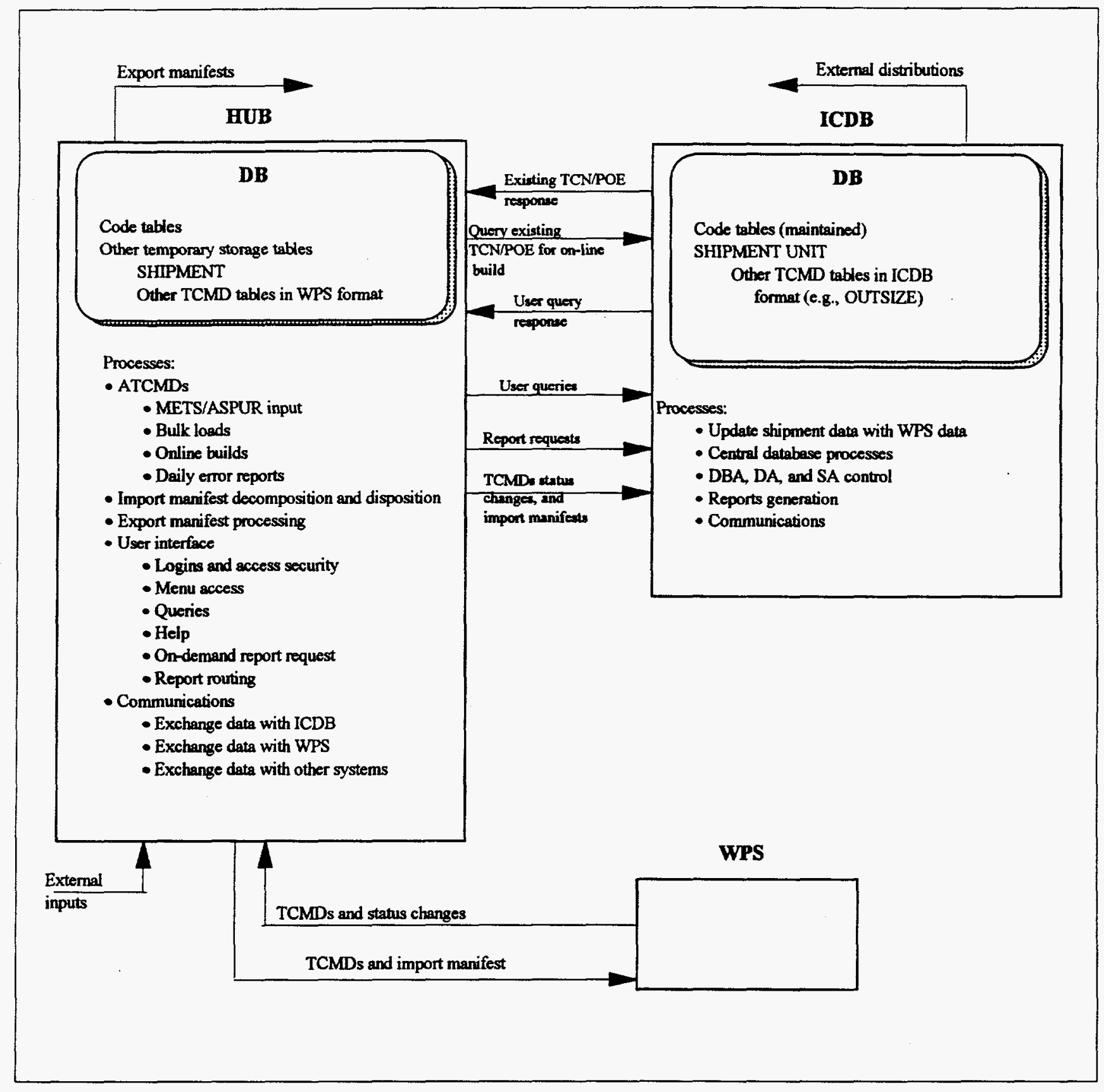

Figure 1.1. Location of database tables and processing modules, IOC processes. 
During development, each site was responsible for testing its own code. For integration testing, ORNL, IME, and the PMO all participated in testing. If additional reviewers (for example, functional users) assisted in the ICDB review process, the PMO made these arrangements. For the final testing with WPS, arrangements were made by WPS management and PMO to obtain test sets and to establish test procedures. ORNL also provided test data and a test plan. WPS and PMO arranged test sites, schedules, and criteria for acceptance/rejection. The following definitions were used in the ICDB testing process:

- Site development testing. Each site (ORNL, IME) developed test procedures and was responsible for testing the code and processes developed at its own site. This testing took place prior to integration with other code and processes developed by another site.

- Integration testing. This testing ensured that the code and processes developed by ORNL and IME functioned together and provided expected results. The module(s) were tested to ensure that they fulfilled the functional and technical requirements listed in the FD. Test data sets and test procedures were developed by ORNL, IME, and the PMO in collaboration; testing was conducted primarily at ORNL. When problems were discovered during the testing, the problems were documented and the site responsible for the code or process needing correction was responsible for making needed changes. There were no structured walkthroughs or formal documentation produced during these tests.

- In-process reviews (IPRs). IPRs ensured that development progressed on schedule and that requirements were met. The procedures and test data sets were determined by PMO and ORNL and varied according to the state of the development. Some IPRs included reviews by end users. It was hoped that the functional user would be involved as early as possible and on a frequent basis throughout development, especially on those modules that would benefit most from comments by the end user community.

- Reliability testing. Integrated modules were tested for "unexpected" environmental impacts. The procedures for conducting these tests and correcting problems were developed during testing.

- Performance testing. Although ORNL stressed the need for performance testing, this testing did not occur until close to the end of the entire test cycle, at which time the system was tested for its ability to meet specific time and volume requirements. Exact procedures were not predetermined. Actual procedures were to fully load the database with three years of historical data and then to communicate the maximum expected number of records from WPS terminal-level sites through the hubs to the central database server. 
- Communication testing. Exact procedures were not predetermined for ensuring that modules communicated in defined or reasonably acceptable ways with other modules, the operating system, or other systems. Actual procedures were established during testing.

- System development test (SDT). The SDT was a formal MTMC test of the ICDB central database and hubs and the terminal-level WPS as a complete and integrated system. Procedures, test data, and schedules were determined prior to the test. ORNL, IME, and PMO participated as required.

- System qualification test (SQT). The SQT was a formal test of ICDB and WPS as a complete system. Procedures, test data, and schedules were the same as were used for SDT. ORNL, IME, and PMO participated as required.

\subsection{ASSUMPTIONS}

Dependencies for specific modules were included within each separate section; however, the tasks and schedules listed in this design report were all dependent on these factors:

- That WPS design would be stabilized ("frozen") so that development of programs could progress with a stable database design, operational platform design, etc. (Note: WPS terminal-level development continued throughout testing. Changes to WPS programs, especially to code that was directly involved with data exchanges between ICDB and the terminal system, frequently caused unexpected results in ICDB.)

- That the operational architecture (hardware, communications lines, operating system, RDBMS, and software tools) would be available in time to write and/or convert and test appropriate programs, code, and/or applications that needed to be written and/or converted from programs, code, and/or applications written on the developmental platform. (Note: although the production hardware was available, upgrades were made throughout the development and testing cycle. Usually, the decision to upgrade was appropriate, but the lack of a stable architecture necessitated a considerable amount of retesting to ensure that the upgrade didn't affect already written/tested code.)

\subsection{ACRONYMS AND ABBREVIATIONS}

A-2000 Autostrad-2000

ASPUR Automated System for Processing Unit Requirements

ATCMD Advance Transportation Control and Movement Documents

ICDB Design Plan

November 22, 1995 


$\begin{array}{ll}\text { CASE } & \text { Computer-Assisted Software Engineering } \\ \text { CONUS } & \text { Continental United States } \\ \text { DCSIM } & \text { Deputy Chief of Staff for Information Management } \\ \text { EDI } & \text { Electronic Data Interchange } \\ \text { FD } & \text { Functional Description } \\ \text { FTP } & \text { File Transfer Protocol } \\ \text { HHG } & \text { Household Goods } \\ \text { HP } & \text { Hewlett Packard } \\ \text { ICDB } & \text { Integrated Cargo Database } \\ \text { IME } & \text { Information Management, Eastern Area } \\ \text { IOC } & \text { Initial Operating Capability } \\ \text { MAISRC } & \text { Major Army Information System Review Committee } \\ \text { METS } & \text { Mechanized Export Transportation System } \\ \text { MTMC } & \text { Military Traffic Management Command } \\ \text { NFS } & \text { Network File System } \\ \text { OCONUS } & \text { Outside the Continental United States } \\ \text { ORNL } & \text { Oak Ridge National Laboratory } \\ \text { PC } & \text { Personal Computer } \\ \text { PMO } & \text { Product Management Office } \\ \text { RDBMS } & \text { Relational Database Management System } \\ \text { RCP } & \text { Remote Copy } \\ \text { SAT } & \text { System Acceptance Test } \\ \text { SDT } & \text { System Development Test } \\ \text { SQT } & \text { System Qualification Test } \\ \text { TBD } & \text { To Be Determined } \\ \text { TCN } & \text { Transportation Control Number } \\ \text { USAISC } & \text { United States Automated Information Systems Command } \\ \text { WA } & \text { Western Area } \\ \text { WPS } & \text { Worldwide Port System } \\ \text { 3GL } & \text { Third-Generation Language } \\ \text { 4GL } & \text { Fourth-Generation Language } \\ & \\ & \end{array}$

\subsection{REFERENCES}

Military Traffic Management Command. Directorate of Information Management Product Management Office. Worldwide Port System (WPS) Regional Integrated Cargo Database (ICDB) Interface with the Worldwide Port System (WPS) Terminal System: Concept of Operation and Detailed Specification. UNCLASSIFIED. January 1993.

Oak Ridge National Laboratory. Database Specifications for the Worldwide Port System (WPS) Regional Integrated Database (ICDB). UNCLASSIFIED. ORNL/TM-12725. March 1994. 
Oak Ridge National Laboratory. Architectural Analysis for the Worldwide Port System (WPS) Regional Integrated Database (ICDB). UNCLASSIFIED. ORNL/TM-12357. April 1993.

Oak Ridge National Laboratory. Functional Description for the Worldwide Port System (WPS) Regional Integrated Database (ICDB). UNCLASSIFIED. DRAFT November 1992, revised January 1993, revised November 1993. To be published as ORNL/TM13118, expected November 1995.

Oak Ridge National Laboratory. Project Plan for the Worldwide Port System (WPS) Regional Integrated Database (ICDB). UNCLASSIFIED. FINAL. February 1993.

Oak Ridge National Laboratory. Standards and Conventions for the Worldwide Port System (WPS) Regional Integrated Cargo Database (ICDB). UNCLASSIFIED. ORNL/TM-12799. February 1995.

Oak Ridge National Laboratory. System Administration/System Operation Report for the Worldwide Port System (WPS) Regional Integrated Cargo Database (ICDB) Development System. UNCLASSIFIED. DRAFT, October 1992; FINAL, December 1992.

Oak Ridge National Laboratory. System/Subsystem Specifications for the Worldwide Port System (WPS) Regional Integrated Cargo Database (ICDB). UNCLASSIFIED. FINAL DRAFT, September 1995. To be published as ORNL/TM-13119, expected November 1995.

USAISC. Management Plan: AUTOSTRAD Modernization Program (A-2000). UNCLASSIFIED. January 1989.

Worldwide Port System. WPS Database Specification. UNCLASSIFIED. FINAL, December 1991. 


\section{DEVELOPMENT STRATEGY: FUNCTIONAL REQUIREMENTS}

The ICDB functional requirements are described in the ICDB FD, Section 3.2. Functional processes are accessed from a menu screen. Functional users with unlimited access see the following options:

- ATCMD Processes

- Manifest Processes

- Inquiry

- Reports

- Regional Processes

- Utilities

It should be noted that the process flows as given in the figures of this chapter were for IOC CONUS capabilities only. In the future, enhancements may change the flow [e.g., when ICDB hubs exist Outside CONUS (OCONUS), the flow of manifest data will be via Oracle table format from export to import rather than via 80-column flat files] and format [e.g., ATCMDs may be transmitted to the processing module via electronic data interchange (EDI) format] of data to ICDB.

\subsection{ATCMD PROCESSING}

Development activities for ATCMD processing included both batch processing, which was automated to occur without user intervention, and on-line processes, which were accessible from the functional process main menu screen by choosing option 1 . The process flows are shown in Fig. 2.1. During development planning, it was decided that the ATCMD tables (see Fig. 2.1) would be in the format of WPS cargo export (XSHIPMENT) and "trailer data" (e.g., XOUTSIZE, XEXPLOSIVE) Oracle tables. These ATCMD tables would be used to temporarily hold ATCMD data before the ICDB communications process transmitted the data to the ICDB central database and to WPS (see also Section 3.2). 


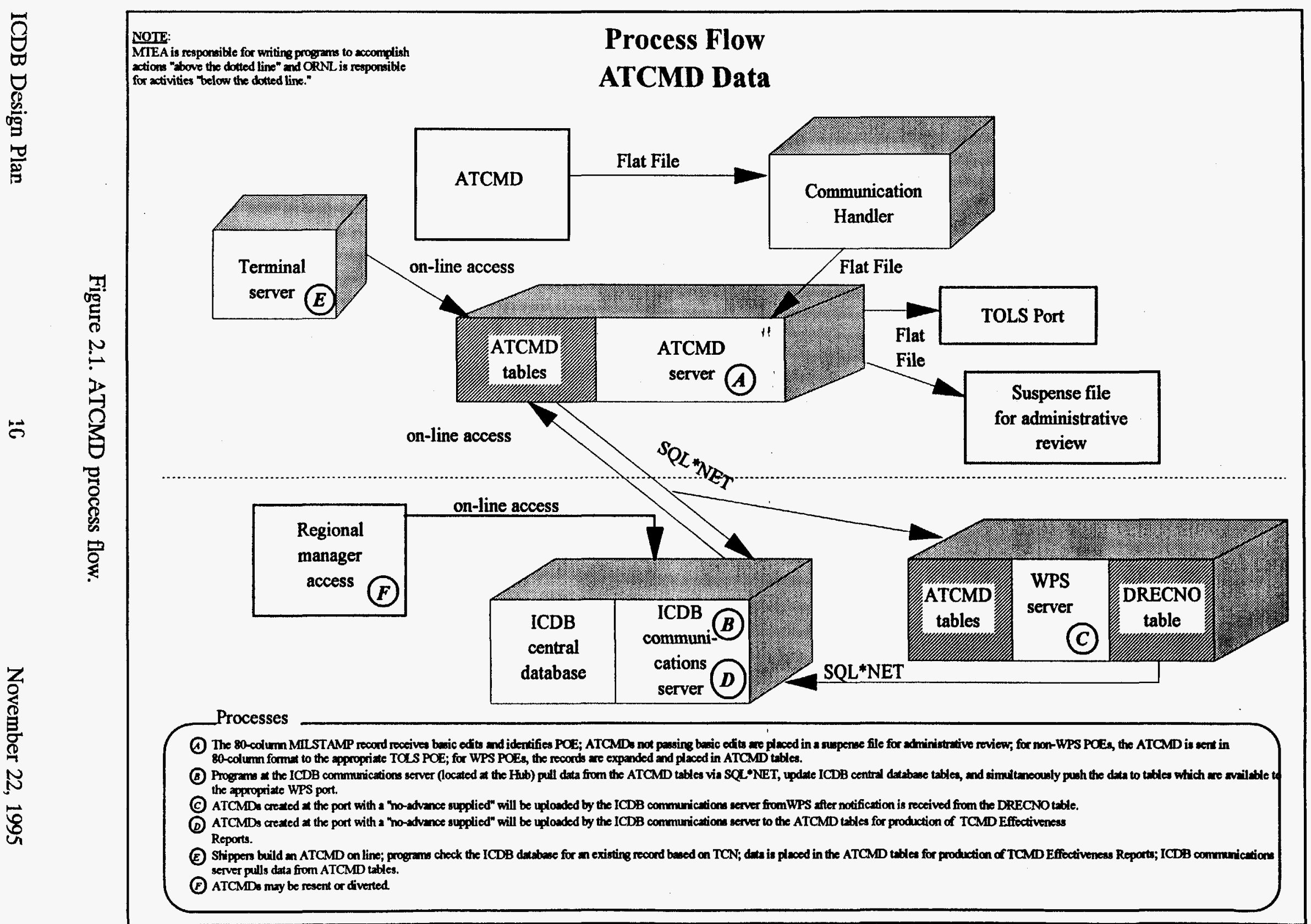




\subsubsection{Design and Development Tasks}

ATCMD development concentrated around two tasks: batch input [including processing of batch ATCMDs, conducting the daily error process, and processing Mechanized Export Traffic System (METS) pre-advance TCMDs] and on-line services (including ATCMD resend/divert functions and ATCMD on-line build). Specific developmental tasks are listed below.

\section{Batch ATCMD Processes}

1. Process ATCMD (Timed procedure, frequent executions).

(1) Concatenate ATCMD files from all sources.

(2) Validate 80-character record length.

(3) Call SQL*Loader to input ATCMD file to intermediary 80-column format table with sequence number added.

(4) Call PL/SQL to validate TCN, POE, DIC.

(5) Call PL/SQL to extract TOLS data to hold table (INTERIM).

(6) Call PL/SQL validation routines:

a. Reject trailers without primes.

b. Reject contents without container primes.

c. Expand TCON to full van number.

c. Convert MILSTAMP overpunches to standard numeric.

d. Insert GBL header data.

e. Expand vehicle records.

(7) Call PL/SQL to remove rejects from temporary table and move to reject table.

(8) Call PL/SQL to decompose remaining 80 -column records to WPS format.

2. Daily Error Process (once daily).

(1) Call PL/SQL to extract TOLS records, clear hold table.

(2) Call SQL*Plus to prepare reject list.

(3) Call PL/SQL to purge reject table of records $>5$ days.

(4) Call PL/SQL to edit and mark TCMD effectiveness errors.

(5) Call SQL*Plus to prepare TCMD effectiveness outputs.

3. METS Pre-Advance TCMD Process (timed to coincide with METS cycles).

(1) Concatenate METS data, verify record lengths.

(2) Call SQL*Loader to load to temporary tables.

(3) Call PL/SQL to decompose to WPS format. 


\section{ATCMD On-line Services}

1. ATCMD On-Line Build.

(1) Main Menu Choice "ATCMD Processes"; subchoice "Build ATCMD."

(2) Subprocesses: build a van record and add contents; build a breakbulk record; build an empty van record.

2. ATCMD Resend/Divert ATCMD by Container Number.

3. ATCMD Resend/Divert ATCMD by TCN.

\subsubsection{Responsibilities}

IME had primary responsibility for this module. IME designed and developed the programs that accomplished the batch processing tasks described in Section 2.1.1. ORNL was responsible for writing the SQL*Net code that periodically read data from the ATCMD tables produced by IME in order to (1) upload the data to the central ICDB and (2) make the data accessible to the appropriate WPS site. ORNL was aiso responsible for writing the SQL*Net code that retrieved "no-advance-received" ATCMD data from WPS sites, loaded it to ICDB, and made sufficient data available to the ATCMD module for production of the TCMD effectiveness reports. IME was responsible for compiling the data needed for the TCMD effectiveness reports. ORNL was responsible for making the TCMD effectiveness data available to appropriate recipients. For the ATCMD on-line processing, IME was responsible for the ATCMD on-line build functionality and ORNL was responsible for the resend/divert functionalities.

ORNL was responsible for marking the records after they had been read. This flagging of a read record occurred on both the ATCMD processing module DRECNO table and on the WPS DRECNO table. 


\subsubsection{Dependencies}

The successful integration of this task was dependent on the following: (1) IME was dependent on ORNL for the menu structure leading to this module; (2) ORNL was dependent on IME to populate the tables from which the data was selected for insertion into the database and for sending to WPS; (3) ORNL was dependent on WPS for "freezing" the WPS tables; (4) IME was dependent on ORNL for supplying no-advancesupplied data from WPS to the ATCMD processing module for production of TCMD effectiveness reports; (5) PMO was responsible for determining the recipients of this report and how they should receive it; (6) IME was dependent on ORNL for the reference tables.

\subsubsection{Development Schedule}

Table 2.1 presents the original schedule for development of the tasks listed in Section 2.1.1. IME and ORNL agreed to begin exchanging data and programs as early as possible. It was critically important that each site and the PMO review the development progress periodically and not wait until the due date to attempt to integrate the various processing modules with the communication routines and the central database. (Additional schedules for testing are presented in Appendix A.)

Table 2.1. ATCMD development schedule.

\begin{tabular}{||l|l|l||}
\hline \multicolumn{1}{|c|}{ Activity } & \multicolumn{1}{c|}{ Start } & \multicolumn{1}{c|}{ Complete } \\
\hline Design ATCMD module & Feb 93 & 2 Apr 93 \\
\hline Present ATCMD design details to PMO/DCSIM & Apr 93 & Apr 93 \\
\hline Develop ATCMD modules & Apr 93 & 3 Sep 93 \\
\hline Documentation & Sep 93 & Nov 93 \\
\hline Transition to production system & Nov 93 & Dec 93 \\
\hline
\end{tabular}




\subsection{IMPORT MANIFEST DECOMPOSITION AND DISTRIBUTION}

Import manifest processing included both batch processing, which was automated to occur without user intervention, and on-line processes, which were accessible from the functional process main menu screen by choosing option 2 . This module provided capabilities to receive and perform a basic edit on 80 -column import manifests; decompose the 80 column format according to WPS requirements; distribute the manifests to appropriate port(s); resend or divert, as appropriate; and conduct other import manifest "business" as described in Section 2.2.1. The process flows are shown in Fig. 2.2. During development planning, it was decided that the manifest tables (Fig. 2.2) would be in the format of the WPS cargo import (SHIPMENT) and "trailer data" (e.g., OUTSIZE, EXPLOSIVE) Oracle tables. These manifest tables would be used to temporarily hold import manifest data before the ICDB communications process transmitted the data to the ICDB central database and to WPS (see also Section 3.2).

\section{Design and Development Tasks}

Import manifest development concentrated around two tasks: batch processing and on-line processing. Specific developmental tasks are listed below.

\section{Batch Import Manifest Processing}

1. Process Import Manifest. (Timed procedure, many times daily.)

(1) Concatenate files from various sources.

(2) Validate 80-character record size.

(3) Call SQL*Loader to load data to 80 column interim table.

(4) Call PL/SQL to extract TOLS manifests to hold table (INTERIM).

(5) Call PL/SQL to decompose to WPS format tables.

2. TOLS Extract. (INTERIM, timed procedure, once daily $1930 \mathrm{hrs}$.)

(1) Call PL/SQL to extract TOLS hold table to flat file and purge. 


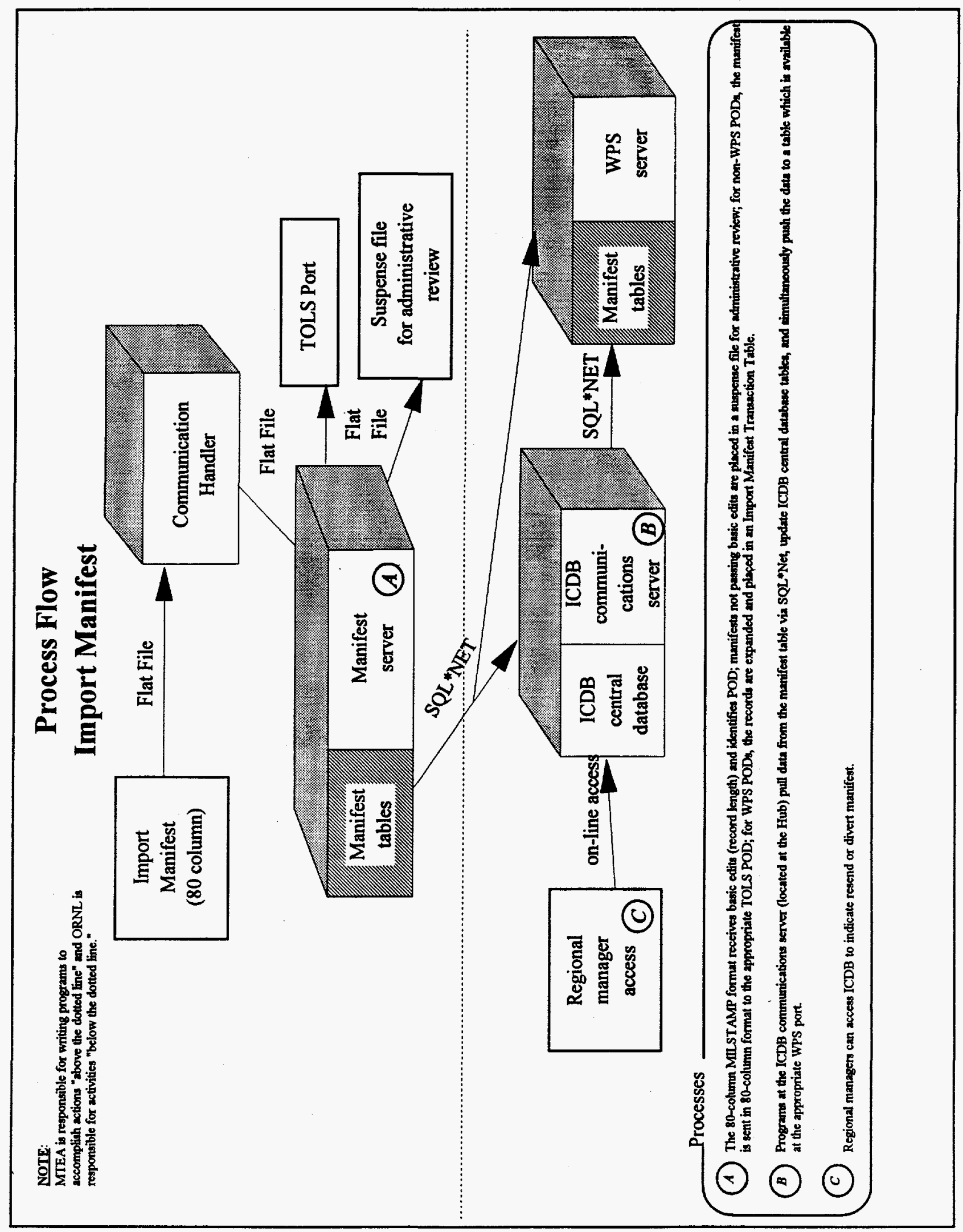

Figure 2.2. Import manifest process flow.

ICDB Design Plan 


\section{On-line Import Manifest Services}

1. Import Manifest Resend/Divert Entire Manifest.

2. Import Manifest Resend/Divert Manifest by Container Number.

3. Import Manifest Resend/Divert Manifest by TCN.

\section{2 .2 Responsibilities}

IME had primary responsibility for the batch processes of this module, and ORNL had responsibilities for the resend/divert functionalities. IME designed and developed the batch programs that accomplished the tasks described in the ICDB FD. ORNL was responsible for writing the SQL*Net code that periodically read the manifest data processed by the module in order to (1) upload the data to the central ICDB, (2) make the data accessible to the appropriate WPS site, and (3) mark the records in the hub's DRECNO table after reading. ORNL was responsible for writing the code and developing the screens for the resend/divert manifest processes. IME provided the requirements for this functionality and recommended a design approach.

\subsubsection{Dependencies}

The successful integration of this task was dependent on the following: (1) IME was dependent on ORNL for the menu structure leading to this module; (2) ORNL was dependent on IME to use the agreed-upon format and for populating the tables from which the data was selected for insertion into the database and for sending to WPS;

(3) ORNL and IME were dependent on WPS for "freezing" the WPS tables; (4) IME was dependent on ORNL for the reference tables. 


\subsubsection{Development Schedule}

Table 2.2 presents the original schedule for development of the tasks listed in Section 2.2.1. (Additional schedules for testing are presented in Appendix A.)

Table 2.2. Import manifest processing development schedule.

\begin{tabular}{||l|l|l||}
\hline \multicolumn{1}{|c|}{ Activity } & \multicolumn{1}{c|}{ Start } & \multicolumn{1}{c|}{ Complete } \\
\hline Design manifest module & Feb 93 & 2 Apr 93 \\
\hline $\begin{array}{l}\text { Develop prototype manifest distribution module for } \\
\text { SUN630 Oracle/ADA demonstration and evaluation }\end{array}$ & $8 \mathrm{Feb} 93$ & 19 Mar 93 \\
\hline Develop manifest distribution module & Apr 93 & 3 Sep 93 \\
\hline Transition to production system & Nov 93 & Dec 93 \\
\hline
\end{tabular}

\subsection{EXPORT MANIFEST PROCESSING}

This process was originally delegated to IME for design and development. The module provided capabilities to receive export manifests, supplements, and adjustments from WPS; distribute the manifests, supplements, and adjustments to appropriate recipients; retransmit, as appropriate; and conduct other export manifest "business." IME was unable to complete the functionality in the desired time frame, and this responsibility was assigned to the WPS terminal-level developers at MTMC Western Area (WA). Because the design, the responsibilities, the dependencies, and the schedule changed significantly from that which was in the original Design Plan, this information is not included in this revised document.

\subsection{INQUIRY}

The ICDB query option was a method of selecting and displaying infrequently needed information. The query option provided capabilities that were neither completely 
preformatted reports nor completely ad hoc requests. The option for obtaining standard, preformatted, predefined, printed reports was made available (see Section 2.5, "Reports Production"). The option to request a truly ad hoc query was made available through the inquiry menu option; however, this option was limited to a select group of users.

The query process was made accessible from the functional process main menu screen by choosing option 3 . The Inquiry submenu included options to perform a query on a single cargo shipment, to perform aggregate queries, or to formulate an ad hoc query. Options that the user might select are as follows:

- The user chooses the query option from the menu screen and then chooses the appropriate type of query (e.g., single shipment, multiple shipment -- detail, multiple shipment -- summary, ad hoc).

- Single: If the user chooses a single-shipment query option, he chooses the type of shipment query (POV, HHG, etc.).

- Single: For a single-shipment query option, the user enters the appropriate shipment identifier (TCN or a combination of TCN and another data field).

- Single: A screen that displays a standard set of information (e.g., current status) is returned.

- Multiple, detail: If the user chooses to perform an aggregate query, he chooses the query type (e.g., hazardous, household goods).

- Multiple, detail: For an aggregate query option, the user must enter appropriate parametric information to identify and limit the conditions of the query.

- Multiple, detail: The screen that displays a standard set of information for every cargo shipment fulfilling the conditions of the query is returned.

- Multiple, summary: If the user wishes to see summary detail (e.g., how many total shipments), he chooses this query type and inputs limiting parameters.

- Multiple, summary: The screen that displays the requested aggregate information is returned.

- Ad hoc query: The system provides access to a third-party vendor software package which can be used to formulate an ad hoc query.

- For some queries, the user is given the option to return information to the screen, save to a file, or print a hard copy of information returned with a query. 
Process flows for this module are as follows:

- After logging in to the hub through the user interface, the user selects a query type, identifies appropriate identifiers and/or parameter delimiters, and requests that the query be executed.

- The query is executed against the central ICDB database.

- The user receives the output in the appropriate manner (screen, printer, file).

\subsubsection{Design and Development Tasks}

The following design and development tasks were accomplished.

- Met with the users to determine frequently performed single and aggregate queries and to review screen designs and functionality.

- Designed query types that were used to identify the displayed columns for singleshipment query types.

- Designed query types that were used to identify the displayed columns for multipleshipment query types.

- Designed both types of query screens.

- Designed parameter selection screen.

- Designed output display screens.

- Designed screens for pop-up windows associated with the various screen types (e.g., list of valid values displays from code tables).

- Established criteria and standards for help messages and error messages.

- Wrote SQL code for checking the existence of a TCN and other data fields (as needed) in the database.

- Wrote SQL code for performing queries.

- Tested SQL code against real shipment data. 
- Determined time required for completing query and alerting user; designed mechanism for presenting this information to the user and allowing the user to make a decision on whether to continue.

- Mapped IQ to the ICDB data elements and wrote code to incorporate IQ capability.

\subsubsection{Responsibilities}

ORNL had primary responsibility for this module. ORNL designed and developed the programs that accomplished the requirements described in Section 2.4.1. PMO was responsible for arranging user reviews and user input for query design. Originally IME was assigned responsibility for providing the hooks to IQ; however, ORNL assumed this responsibility in late 1994.

\subsubsection{Dependencies}

ORNL was dependent on a stable database design. ORNL was dependent on the PMO to provide a hardware configuration for testing communications from initial user input through the hub processing center to the central database server and back again with the response to the inquiry. ORNL was dependent on the PMO for arranging user demonstrations and reviews.

\subsection{Development Schedule}

The original schedule for completion of the above tasks is presented in Table 2.3. (See Appendix A for additional schedules.) 
Table 2.3. Inquiry module development schedule.

\begin{tabular}{||l|l|l|l||}
\hline \multicolumn{1}{|c|}{ Activity } & \multicolumn{1}{|c|}{ Start date } & Initial test date & Complete date \\
\hline $\begin{array}{l}\text { Multiple shipment, detailed } \\
\text { information }\end{array}$ & May 1,93 & June 25, 93 & Oct 1, 93 \\
\hline $\begin{array}{l}\text { Multiple shipment, summary } \\
\text { information }\end{array}$ & May 1,93 & $*$ & $*$ \\
\hline Single shipment & May 28,93 & Aug 6, 93 & Oct 14,93 \\
\hline Ad hoc queries & $* *$ & $* *$ & $* *$ \\
\hline
\end{tabular}

*Multiple shipment summary screens were not defined until early 1994 . Prototype screens were provided for review and four reports providing aggregate summary data in a format determined by users as appropriate were included in the final version.

** Responsibility for hooking in the IQ software was not assigned to ORNL until late 1994; no dates for its inclusion were included in the original version of this table.

The testing program for this module was slightly different from the testing required for Sections 2.1-2.3 because of the need for frequent user input. Development site testing and review were a continuous process. Functional testing (user reviews) were conducted by PMO. Integration testing was necessary to test interaction of this module with the ICDB database and with the user interface; however, both of these were integral parts of the module. Reliability testing, performance testing, and communication testing were critical measures of success, and these tests were continuous during development.

\subsection{REPORTS PRODUCTION}

This section was not developed for the Design Plan produced in May 1993. Therefore, only a brief summary will be included here.

Initially, IME was responsible for the Reports module. However, because of other responsibilities, IME was unable to complete this task during the required time frame. In December 1994, ORNL was assigned this responsibility. ORNL subdivided the Reports module into the following subgroups: Cargo Management and Documentation, Terminal Operations, Command-Level Reports, and Manifest-Specific Reports. A total of ten 
reports were provided with the system at IOC, some produced by ORNL and some by IME. Some reports could be sent to the screen as well as to a printer or a file. Some reports were compiled at the time of the request and some that were compiled during off hours and stored as a file. Other reports will be developed by the maintenance contractor.

\section{REGIONAL PROCESSES}

This section was not fully developed at the time the Design Plan was originally produced. Therefore, only a brief summary will be included here. The functionalities included in this module are listed below with the site responsible for development also listed.

- Edit ATCMDs

- Edit Import Manifests

- Edit TACs

- Print Reject Listing

- Maintain Central Database Code Tables

- Maintain Code Tables Distributed to WPS

- Monitor Automated Data Extracts

- Update Discharge Dates

- Print Open Discharge Dates Listing
IME

IME

IME

ORNL/IME

ORNL

ORNL

ORNL

ORNL

ORNL

For the option to "Print Reject Listing," ORNL prepared the screen that let the user print the listing, and IME prepared the listing. The option to "Monitor Automatic Data Extracts" included functionality (1) to resend any of the data files and (2) to change the frequency of transmittal to GTN.

\subsection{UTILITIES}

This section was not included in the original Design Plan produced in May 1993. It was added to enable users (1) to print or download files produced through the ad hoc query capability (see Section 2.4) and (2) to print or download other files (primarily queries which had been saved to files). ORNL was responsible for this module. ORNL was assisted by personnel from the WPS development team at MTMC WA. 


\section{DEVELOPMENT STRATEGY: SYSTEM REQUIREMENTS}

These system requirements are described in the ICDB System/Subsystem Specifications (see Section 1.7 for reference to the most recent version). Scripts were developed to assist with system and database administration and with communications. ORNL was responsible for the development of this entire subsystem. The System Administration/Database Administration (SA/DBA) module was accessible only to system personnel (i.e., the System Administrator and the Database Administrator). The communication scripts operate in the background.

\subsection{SYSTEM ADMINISTRATION/DATABASE ADMINISTRATION}

Table 3.1 shows the tasking effort on the SA/DBA module. End dates represent initial completion; these tasks, and these specific scripts, were revised with each acquisition of hardware, software, and operating system upgrades.

Table 3.1. System and database administration modules.

\begin{tabular}{|c|c|c|c|c|}
\hline Module/submodule & Start & End & Scripts & Comments \\
\hline Menu Structure & Aug 18, '93 & Apr 30, '94 & & Updates throughtout development \\
\hline $\begin{array}{l}\text { System Administration: } \\
\text { Managing users \& processes } \\
\text { User registration } \\
\text { Managing devices } \\
\text { Auditing } \\
\text { Backup } \\
\text { Network } \\
\text { Cron }\end{array}$ & $\begin{array}{l}\text { Jun } 7, ' 93 \\
\text { Jan } 1,94 \\
\text { Aug } 23,93 \\
\text { Sep } 13 \text { '93 } \\
\text { Sep } 20 ' 93 \\
\text { Sep } 20 ' 93 \\
\text { Sep } 20 \text { '93 }\end{array}$ & $\begin{array}{l}\text { Jun } 15, ' 93 \\
\text { Apr } 15,94 \\
\text { Aug } 27, ' 93 \\
\text { Apr } 21,94 \\
\text { Feb } 1{ }^{\prime} 94 \\
\text { Sep } 24 \\
\text { Feb } 1 \text { '94 }\end{array}$ & $\begin{array}{l}-5 \\
-2 \\
-5 \\
-2 \\
-2 \\
-2\end{array}$ & $\begin{array}{l}\text { Not including adding users (menu) } \\
\text { Disk usage, backup devices } \\
\text { Audit system usage } \\
\text { Manual backups } \\
\text { Monitor network } \\
\text { Manage cron resources }\end{array}$ \\
\hline $\begin{array}{l}\text { Database Administration: } \\
\text { Database structure } \\
\text { Objects } \\
\text { Constraints, dependencies, } \\
\text { procedures } \\
\text { Profiles, roles, privileges } \\
\text { Auditing } \\
\text { Errors } \\
\text { Exports }\end{array}$ & $\begin{array}{l}\text { Aug } 23 \text { '93 } \\
\text { Jun } 7 \text { '93 } \\
\text { Jun } 15 ' 93 \\
\text { Aug } 7 \text { '93 } \\
\text { Aug } 14 ' 93 \\
\text { Sep } 6 \text { '93 } \\
\text { Sep } 20 ' 93\end{array}$ & $\begin{array}{l}\text { Aug } 27 \text { '93 } \\
\text { Aug } 7 \text { '93 } \\
\text { Aug } 7 \text { '93 } \\
\text { Aug } 21 ' 93 \\
\text { Aug } 31 ' 93 \\
\text { Sep } 10 ' 93 \\
\text { Feb } 1 \text { '94 }\end{array}$ & $\begin{array}{l}\sim 5 \\
\sim 10 \\
\sim 5 \\
\sim 10 \\
\sim 5 \\
\sim 5 \\
\sim 1\end{array}$ & $\begin{array}{l}\text { Tablesp., data files, rollbacks, etc. } \\
\text { Tables, indexes, links, synonyms, } \\
\text { views, etc. } \\
\text { Object modifiers } \\
\text { Object security } \\
\text { Audit db usage at various levels } \\
\text { Object errors } \\
\text { Recent db exports }\end{array}$ \\
\hline Site/modem regist./ maint. & Apr '94 & May '94 & & \\
\hline Wrapup and integration & Jan 1 '94 & May'94 & & \\
\hline
\end{tabular}


The system administrator and backup personnel perform tasks such as those listed below to fulfill the SA requirements. Although it was assumed that many of these procedures would be done manually by the system administrator, some procedures were set up to be accessed from a menu screen seen only by authorized SA/DBA users.

- set-up computer system and install the operating system,

- conduct full or partial file system backups on a periodic basis,

- perform file system recovery as needed,

- diagnose system and network problems,

- maintain an audit trail, as needed,

- check and monitor usage and user activities,

- monitor and tune the operating system parameters and files for performance,

- install or assist in installation of software packages,

- provide support for system users,

- install or remove peripheral hardware as needed,

- add/change/delete userids and user information,

- add/change/delete site information,

- add/change/delete modem information,

- add/change/delete transfer recipients (in conjunction with data administrator),

- maintain DBA code tables.

Personnel responsibilities for database administration are listed in the ICDB FD. ORNL recommended that standard software utilities provided by Oracle (SQL*DBA) be used as much as possible (at least initially). Scripts were also developed to modify configurations, maintain physical tables, and query the condition of the database. The DBA must be able to monitor all database aspects of background processes in order to tune the database for better performance. 


\subsubsection{Design and Development Tasks}

The specific tasks necessary to fulfill the functional requirements of system administration were revised upon implementation of operational system hardware, operating system, and software tools. ORNL developed an ICDB SA/DBA module which was totally separate from the ICDB functional menu system. This SA/DBA menu system provided automated capabilities to monitor and manage the system. The SA/DBA module was modified as needed during development. A detailed description of this module is given in the System/Subsystem Specifications.

\subsubsection{Responsibilities}

ORNL was responsible for developing the automated tools that the ICDB System Administrator and Database Administrator could use for fulfilling Sa/DBA duties. These tools were developed, tested, and used on the developmental platform and then implemented on the operational system platform prior to final system testing.

\subsubsection{Dependencies}

ORNL was dependent on PMO to provide the operational hardware for testing in a timely manner. ORNL was dependent on PMO to provide reviews of the SA/DBA module.

\subsubsection{Development Schedule}

The time frame for development of an SA strategy was dependent upon review of the final hardware platform and determination of the actual tasks required to develop appropriate SA/DBA functionality. (Proposed delivery of operational hardware was 
November 1993.) Scripts were written for the development platform and rewritten for the operational platform.

\subsection{COMMUNICATIONS}

Because ICDB received data from multiple sites and supplied information to multiple systems and organizations, the communications capabilities were critically important. Options for various communications choices are described at length in the ICDB Architectural Analysis and will not be repeated here. The communications requirements from a functional point of view (i.e., what is required to fulfill the functionality of ICDB) are itemized in Section 3.2.1.

\subsubsection{WPS/Hubs/ICDB}

Communications processes were automated to execute as background processes. These processes transferred data among WPS, the hubs, and the central ICDB server. The data communications links between the ICDB central server Oracle7 data tables and the hub Oracle7 data tables were primarily by SQL*Net. Secondary or backup data communication between ICDB and the hubs was by flat files but this method was used only under unusual circumstances such as rebuilding Oracle7 tables from backup flat file data. Under ordinary circumstances, the method of transfer for Oracle7 data was via SQL*Net.

Transfers of non-Oracle7 data among WPS, the hubs, and the central ICDB was designed to be via Remote Copy (RCP).

Table 3.2 shows tasks and specific scripts for accomplishing the communications tasks. 
Table 3.2. Communication module.

\begin{tabular}{|c|c|c|c|c|}
\hline Module/submodule* & Start & End & Scripts & Comments \\
\hline $\begin{array}{l}\text { CRON-driven scripts } \\
\text { Every } 1 \mathrm{~min} \\
\text { Every } 5 \mathrm{~min} \\
\text { Daily } \\
\text { Monthly } \\
\text { As required }\end{array}$ & $\begin{array}{l}\text { Nov } 93 \\
\text { Apr } 93 \\
\text { Nov } 93 \\
\text { Nov } 93 \\
\text { Jul } 93\end{array}$ & $\begin{array}{l}\text { Feb } 94 \\
\text { Mar } 94 \\
\text { Feb } 94 \\
\text { Feb } 94 \\
\text { Aug } \\
95^{* *}\end{array}$ & $\begin{array}{l}1 \\
1 \\
1 \\
1 \\
\text { Aug } 95\end{array}$ & $\begin{array}{l}\text { Health check (from server) } \\
\text { Extract WPS data } \\
\text { Backups } \\
\text { Archive } \\
\text { Automated data exchanges }\end{array}$ \\
\hline $\begin{array}{l}\text { Condition-driven scripts } \\
\text { Communication failure } \\
\text { Communication overload } \\
\text { Remote failure } \\
\text { Interfaces with } \\
\text { other systems } \\
\text { Code table distribution }\end{array}$ & $\begin{array}{l}\text { Nov } 93 \\
\text { Nov } 93 \\
\text { Nov } 93 \\
\text { Jul } 93 \\
\text { Mar } 94\end{array}$ & $\begin{array}{l}\text { Mar } 94 \\
\text { Mar } 94 \\
\text { Mar } 94 \\
\text { Aug } 95 \\
\text { Aug } 95\end{array}$ & $\begin{array}{l}1 \\
1 \\
1 \\
\text { Aug } 95 \\
\text { Aug } 95\end{array}$ & $\begin{array}{l}\text { Dial backup } \\
\text { Dial backup } \\
\text { Failover/notify }\end{array}$ \\
\hline $\begin{array}{l}\text { User-login implementation } \\
\text { At ICDB } \\
\text { At user's PC }\end{array}$ & $\underset{* * *}{\text { May }}$ & $\underset{* * *}{\text { Apr } 94}$ & 1 & $\underset{* * *}{\text { Security/role }}$ \\
\hline
\end{tabular}

*NOTE: Includes only the actual communicating functions themselves; does NOT include functions or applications which USE communications. Also note: the "will to live" aspects are included in the CRON and condition-driven scripts.

**Some communications requirements were not completely defined until the system was in final system testing and acceptance. These are labeled August 95.

***This was the proposed remote login diskette, which was not developed.

\subsubsection{Design and Development Tasks}

The Oracle7 systems on the ICDB central server, each of the hubs, and each of the WPS nodes were connected via Oracle7 SQL*Net Version 2. This network control layer allowed controlled access to any of the tables on any of these machines without regard to their physical location. To reduce the impact upon the operation of WPS, SQL*Net was used to copy data from WPS to the server with minimal processing on the WPS system. Additional processing of data into the appropriate format for the ICDB database was performed on the ICDB server. The actual transfer of data between Oracle7 tables connected by SQL*Net was performed by a set of custom shell scripts and small applications that were started by the system clock or other applications. They executed at regular, predetermined intervals. 
Establishing SQL*Net communications between the development ICDB and development WPS was the first communications component to be implemented. In this task, the operational ICDB/hub/WPS communications links were emulated. The ORNL development SUN Sparc 630 was the original ICDB central server for communications development purposes, and the WPS development system in Oakland was the WPS node. A system with which to emulate a hub did not exist. Later (December 1993) the development system was upgraded to Hewlett Packard (HP) hardware in a configuration which emulated the production architecture.

Following establishment of SQL*Net, development proceeded on other communications processes. The following is a list of these communications processes:

- Checked the health of the system. Processes monitored the operational conditions of the hubs and ICDB central server. These programs sounded the alarm when a communications line failed, a hub failed, or the ICDB server failed. These programs were designed to determine the best way to continue operations when a failure was identified. They checked the hubs, server, and communications lines at regular intervals and also were activated if a failure occurred during a normal communications process. They were designed to execute on the hubs and server to ensure sufficient redundancy for the uninterrupted operation of the system.

- Read CONUS WPS data and wrote the data to the ICDB server. These data included new shipment unit data and updates identified in the WPS DRECNO table, updates recorded in the WPS JOURNAL table, and ship arrival data recorded in WPS tables.

- Read ATCMD processing output on the hubs, wrote the data to the ICDB server, and distributed the data to WPS. This data included both new shipment unit data and updates made by shippers.

- Read import manifest processing output on the hubs, wrote the data to the ICDB server, and distributed the data to WPS.

- Retrieved flat file export manifests from WPS and put them on the hubs for subsequent distribution (see Section 2.3).

- Retrieved flat file FMS files from WPS and put in a specified location on the ICDB server to be retrieved by FMS.

- Determined and programmed other flat file transfers as required. 
- Determined and programmed all necessary communications to transmit query results and report requests/responses.

\subsubsection{Responsibilities}

ORNL was responsible for design, development, and implementation of all communications tasks to implement IOC requirements. These tasks included all tasks listed above.

\subsubsection{Dependencies}

ORNL was dependent on WPS and PMO for providing platforms with which to emulate the operational WPS, ICDB hub, and ICDB Server. ORNL was dependent upon WPS maintaining Oracle7 SQL*Net Version 2 at development sites so that communications processes could be developed and tested under conditions that simulated operational conditions. ORNL was dependent upon IME for completion of ATCMD and Import Manifest processing modules to successfully complete and test processes that read output from these modules. ORNL, IME, and WPS were all dependent upon each other for maintaining accurate database table configurations. ORNL and IME were dependent upon WPS for responding in a timely manner to issues about the ICDB/WPS interfaces and establishing workable procedures.

Successful completion of the communication task with respect to performance testing was dependent on obtaining the communication lines as defined in the ICDB Architectural Analysis and on obtaining sufficient quantities of test data. 


\subsubsection{Development Schedule}

The communications system was to be implemented on the development architecture, debugged and stabilized on this architecture, and then transferred to the operating architecture. Times given in the list below were estimates made at the time the original Design Plan was produced of man-months required to implement the components on the development system. Actual times for ORNL to complete these tasks were usually less than these estimates because the functionality of many tasks overlapped. Also the time required to port the system from the development architecture to the operational platform was minimal because the code was deliberately designed for portability.

- Establish SQL*Net communications -- 1-2 months.

- Read WPS data and write to ICDB server -- 1-2 months.

- Read ATCMD and import manifest module output, write to ICDB server, and make available to WPS -- about 1 month. Note: although the majority of work on this task can occur independently of IME development, its completion can occur only when the associated IME modules are fully implemented.

- Health check -- 3-4 months. The last communications process to be implemented, this concept is totally new and not supported by any commercial off-the-shelf software.

- Transfer to operational environment -- 0.5-1 month. The timing of completion of this task depends on the availability of the operational system hardware and software.

\subsubsection{ICDB/Other Systems}

The ICDB FD lists multiple systems and organizations with which ICDB must communicate. Most of these data communications were determined to be fixed files sent on a scheduled basis via RCP or File Transfer Protocol (FTP). ORNL was dependent on the PMO to supply file layouts. 


\subsection{USER INTERFACE}

The ICDB user interface software (SQL*Menu and SQL*Forms) was designed to reside on the hubs and central database. Reports generated through the interface (SQL*ReportWriter) were placed on the server. The user interface (i.e., the menus and application screens) was developed using Oracle tools (SQL*Menu, SQL*Forms, and SQL*ReportWriter). The ICDB Standards and Conventions document described screen layouts. Certain features conformed to the design already in place in WPS; however, because WPS was originally written in an earlier version of Oracle and did not take advantage of advances in technology, some of the WPS prototype screen design was modified to employ improved user interface design.

\subsubsection{Design and Development Tasks}

The design tasks were as follows:

- Wrote a Standards and Conventions report.

- Designed a User Interface that took advantage of the latest technologies (e.g., windows) and incorporated modern user interface design theory.

- Demonstrated the User Interface to management and to technical and functional users and incorporated revisions.

- Reviewed all points of human-computer interaction for conformance to the Standards and Conventions report.

- Investigated potential graphical user interfaces.

\subsubsection{Responsibilities}

ORNL was responsible for this task, with input from PMO, IME, and the user community. 


\subsubsection{Dependencies}

ORNL was dependent on PMO for arranging user reviews.

\subsubsection{Development Schedule}

ORNL delivered the Final Draft Standards and Conventions report, which included a description of the screen designs, on May 17, 1993. This report was used during development to reconcile user interface design issues. ORNL reviewed user interface design details as they became available from developers. Sections 2.4-2.7 provide more details on the initial development of user interface screens. 


\section{APPENDIX A}

\section{ICDB TESTING SCHEDULE}

This appendix presents the proposed testing schedule for the Integrated Cargo Database (ICDB) development as of May 28, 1993 (Table A.1). It should be noted that this schedule did not include all individual site testing, nor did it include formal testing with WPS. This schedule was modified during development to accommodate circumstances which delayed development. The actual test schedule of formal testing with the WPS terminal-level system is given in Table A.2. 
Table A.1. ICDB Testing Schedule as of May 28, 1993

\begin{tabular}{|c|c|c|c|c|c|c|c|c|c|c|c|c|c|c|}
\hline Module & $\begin{array}{l}1993 \\
\text { Pre-Mar }\end{array}$ & Mar & Apr & May & Jun & Jul & Aug & Sep & Oct & Nov & Dec & $\begin{array}{l}1994 \\
\text { Jan }\end{array}$ & $\mathrm{Feb}$ & Mar \\
\hline ATCMD & Site & IPR & IPR & IPR & Walk & IPR & Walk & Int,Com & Int,Perf & Int,Rel & Int & Int & & \\
\hline Import Manifest & Site & IPR & IPR & IPR & IPR & IPR & IPR & Walk & Int,Com & Int,Perf & Int,Rel & Int & & \\
\hline Export Manifest & Site & IPR & IPR & IPR & IPR & IPR & IPR & Walk & Int,Com & Int,Perf & Int,Rel & Int & & \\
\hline Queries & Site & IPR & & IPR & & IPR & & IPR & Walk & Int,Rel & Perf & & & \\
\hline Regional Proc. & TBD & & & & & & & & & & & & & \\
\hline Reports & TBD & & & & & & & & & & & & & \\
\hline System Admin. & & & & & Site & Site & Site & Site & Int,Perf & Rel & IPR & IPR & & \\
\hline Data Admin. & Site & Site & Site & Site & IPR & Int & Walk & Rel & & & & & & \\
\hline Database Admin. & & & & & Site & Site & Site & Site & Int,Perf & Rel & Site & Rel & & \\
\hline Communication & Site & Site & Site & Site & Walk & & & Walk & & Int & Perf,Rel & & & \\
\hline User Interface & Site & IPR & Site & IPR & & IPR & & IPR & & IPR & & IPR & & \\
\hline
\end{tabular}

Abbreviations: Site $=$ Site Development Testing; Walk = Structured Walkthroughs; Int = Integration Testing; IPR = In-Progress Reviews; Rel = Reliability Testing; Perf = Performance Testing; Com = Communication Testing; SDT = System Development Testing; SQT = System Qualification Testing. Notes: (1) Site testing occurs throughout development at a specific site. (2) formal system acceptance testing (SDT and SQT) must be scheduled by PMO and WPS management. 
Table A.2. Formal Testing Schedule of the WPS Regional ICDB

\begin{tabular}{||l|l|l||}
\hline \multicolumn{1}{|c|}{ Test } & \multicolumn{1}{c|}{ Dates } & \multicolumn{1}{c|}{ Place } \\
\hline pre-SDT & Jan 9-Jan 20, 1995 & Oakland, California \\
\hline SDT & Jan 30-Mar 3, 1995 & Oakland, California \\
\hline SQT & Apr 24-Jun 1, 1995 & Oakland, California \\
\hline SDT-II & Jul 10-Jul 21, 1995 & Falls Church, Virginia \\
\hline SQT-II & Aug 7-Aug 25, 1995 & Oakland, California \\
\hline
\end{tabular}




\section{INTERNAL DISTRIBUTION}

1.

2.

3.

4.

5.

6.

7.

8.

9.

10-12.
D. Alvic

M. S. Bronzini

G. E. Courville

E. Z. Faby

R. A. Ferguson

J. Fluker

J. W. Grubb

S. G. Hildebrand

S. Moore

J. P. Rollow
13.

14.

15.

16-19.

20.

21.

22-23.

24.

25.
D. E. Reichle

R. B. Shelton

P. C. Shipe

L. F. Truett

Central Research Library

Document Reference Section

Laboratory Records

Laboratory Records - RC

ORNL Patent Office

\section{EXTERNAL DISTRIBUTION}

26. Ms. Betty Childers, ICDB Product Management Office, Military Traffic Management Command, 5611 Columbia Pike, Falls Church, VA 22041-5050.

27. Mr. Herb Kaskoff, WPS Project Management Office, Military Traffic Management Command, 5611 Columbia Pike, Falls Church, VA 22041-5050.

28. Dr. Thomas E. Drabek, Professor, Department of Sociology, University of Denver, Denver, CO 80208-0209.

29-31. Mr. Jack Hetman, ICDB Product Management Office, Military Traffic Management Command, 5611 Columbia Pike, Falls Church, VA 22041-5050.

32. Mr. Robert Loy, Ogden Professional Services, 3211 Jermantown Road, Fairfax, VA, 22030.

33 Mr. Calvin D. MacCracken, President, Calmac Manufacturing Corporation, 101 West Sheffield Avenue, Englewood, New Jersey 07631.

34. Mr. Bob Porter, G3 Future Systems, Office of the Assistant Deputy Chief of Staff for Operations, Military Traffic Management Command, 5611 Columbia Pike, Falls Church, VA 22041-5050.

35. Ms. Lisa Seery, MTIM-B, Military Traffic Management Command, 5611 Columbia Pike, Falls Church, VA 22041-5050.

36. Mr. George F. Sowers, Senior Vice President, Law Companies Group, Inc., 114 Townpark Drive, Suite 250, Kennesaw, GA 30144-5599.

37. Mr. Dave Terry, G3 Future Systems, Office of the Assistant Deputy Chief of Staff for Operations, Military Traffic Management Command, 5611 Columbia Pike, Falls Church, VA 22041-5050.

38. Dr. C. Michael Walton, Paul D. and Betty Robertson Meed Centennial, Professor and Chairman, Department of Civil Engineering, College of Engineering, The University of Texas at Austin, Cockrell Hall, Suite 4.2, Austin, TX 78712.

39. Office of Assistant Manager for Energy Research and Development, DOE-ORO, P.O. Box 2001, Oak Ridge, Tennessee 37831-8600.

40-41. Office of Scientific and Technical Information, U.S. Department of Energy, P.O. Box 62, Oak Ridge, Tennessee 37831. 